\title{
BMJ Open Poor infant and young child feeding practices and sources of caregivers' feeding knowledge in rural Hebei Province, China: findings from a cross-sectional survey
}

\author{
Qiong Wu, ${ }^{1}$ Robert W Scherpbier, ${ }^{2}$ Michelle Helena van Velthoven, ${ }^{3}$ Li Chen, ${ }^{1}$ \\ Wei Wang, ${ }^{1}$ Ye Li, ${ }^{1}$ Yanfeng Zhang, ${ }^{1}$ Josip $\mathrm{Car}^{3}$
}

To cite: Wu $Q$,

Scherpbier RW, van

Velthoven $\mathrm{MH}$, et al. Poor infant and young child feeding practices and sources of caregivers' feeding knowledge in rural Hebei Province, China: findings from a cross-sectional survey. BMJ Open 2014;4: e005108. doi:10.1136/ bmjopen-2014-005108

- Prepublication history for this paper is available online. To view these files please visit the journal online (http://dx.doi.org/10.1136/ bmjopen-2014-005108).

Received 23 February 2014 Revised 10 July 2014 Accepted 11 July 2014 CrossMark

${ }^{1}$ Department of Integrated Early Childhood Development, Capital Institute of Pediatrics, Beijing, China ${ }^{2}$ Health and Nutrition, Water, Environment and Sanitation Section, UNICEF China, Beijing, China

${ }^{3}$ Global eHealth Unit, Department of Primary Care and Public Health, Imperial College London, London, UK

Correspondence to Dr Yanfeng Zhang; summyzh@126.com

\section{ABSTRACT}

Objectives: To obtain a general overview of infant and young child feeding practices in one rural county in China and identify current delivery channels and challenges.

Design: A cross-sectional study.

Setting: A rural county, Zhao County, in Hebei Province, China.

Participants: 10 clusters were first selected within each township (16 townships in total) with proportional to population size sampling. In each cluster, a name list was used to select 13 children aged 0-23 months. We interviewed caregivers of all the selected children.

\section{Primary and secondary outcomes measures:}

Coverage of infant feeding practices, reasons for low coverage of infant feeding practices and current delivery channels of infant feeding practices.

Results: Findings from our survey indicated that infant feeding practices were poor. Early initiation of breastfeeding was only $22.4 \%$, exclusive breastfeeding for 6 months was less than $10 \%$ and continued breastfeeding up to the age of two was just $38.2 \%$. Only $32.5 \%$ of children were given iron-rich or ironfortified foods. The leading sources of infant feeding information were family members, neighbours, friends and popular media. Only around $20 \%$ of the information came from health facilities and nearly none came from communities. Household property data showed that $99.9 \%$ of households owned televisions and $99.4 \%$ owned mobile phones. In addition, $61.2 \%$ of the households owned computers, with $54.8 \%$ having access to the internet.

Conclusions: Few caregivers of children in Zhao County received feeding information during pregnancy and after delivery. Moreover, their feeding knowledge and practices were poor. Multi-channel approaches, delivered through health facilities, community resources, popular media, the internet and mobile phones, hold potential to improve infant feeding practices and should be explored in future studies.

Strengths and limitations: Although this study took place only within one county, a full range of globally

\section{Strengths and limitations of this study}

- The strength of our study is that we collected a full range of globally standard infant feeding indicators as well as information on delivery channels and reasons for coverage failure, which could provide a basis for development of effective IYCF strategies.

- Our study has several limitations. Firstly, the sampling of children was based on the name lists of children in each village. In Zhao County, all live births are reported to the Maternal and Child Health Hospital from all qualified delivery institutions each month. Therefore we obtained the name list from the hospital. Then we sent the name lists to village doctors and asked them to remove children who had died or moved outside the village and add children who were living in the village but who were not on the list. Although all these efforts were made, we are not sure of the completeness of the name lists and selection bias may have occurred. Secondly, some indicators such as initiation of breastfeeding after birth were based on the mothers' recall, with a longest recall time of 2 years, which may have introduced recall bias.

standard feeding indicators was used to assess the feeding practices of caregivers in our study. The name lists of children in some villages may not be complete, and therefore selection bias may have occurred. Some indicators may have recall bias due to long recall time. Trial registration number : ChiCTR-PRC-11001446.

\section{BACKGROUND}

Nutritional status is an important determinant of maternal and child health. ${ }^{12}$ Maternal and child undernutrition is still highly prevalent in low-income and middle-income 
countries and results in significantly increased mortality and morbidity in mothers and children. Suboptimal breastfeeding is a key factor for undernutrition in infants and was estimated to be responsible for 804000 child deaths worldwide in 2011. ${ }^{3}$ Studies have consistently shown that the peak for growth faltering, micronutrient deficiencies and common childhood illnesses occurs from birth up to 2 years of age. ${ }^{3-5}$

Appropriate infant and young child feeding (IYCF) is the basis for child survival, growth and development. ${ }^{3} 467$ The benefits of breastfeeding for both infants and mothers have been well documented in studies, including reducing the risk of morbidity and mortality, especially from infectious diseases such as diarrhoea and pneumonia. ${ }^{8}$ Introducing safe and adequate complementary foods to children aged 6 months helps to fill dietary gaps that cannot be met by breast milk alone. Continued breastfeeding for 2 years or beyond is an essential component of appropriate complementary feeding. ${ }^{10}$

To emphasise the importance of child feeding, the WHO and United Nations Children's Fund (UNICEF) jointly developed the Global Strategy for Infant and Young Child Feeding (IYCF) in 2002. ${ }^{11}$ The recommendations in this strategy state that children should be exclusively breastfed for 6 months after birth, and provided with safe and appropriate complementary foods with continued breastfeeding up to 2 years or beyond. ${ }^{11}$

During the past decade, the Ministry of Health of China (MoHCh) adopted the WHO's IYCF recommendations and implemented programmes to improve nutrition practices. ${ }^{12}{ }^{13}$ However, suboptimal infant feeding is still very common in China. National Chinese data from 2008 showed that only $27.6 \%$ of Chinese children were exclusively breastfed up to 6 months, only $43.3 \%$ of children aged 6-9 months were introduced to solid or semisolid foods, and only $37.0 \%$ of children aged 1215 months received continued breastfeeding. ${ }^{14}$ In addition, introduction of complementary food too early or too late and a restriction in food selection, especially for animal-source food, were widespread in China. ${ }^{15-19}$ In poor rural areas, the rates of exclusive breastfeeding, continued breastfeeding for 1 year and continued breastfeeding for 2 years were $28.7 \%, 55.5 \%$ and $9.4 \%$, respectively. ${ }^{20}$ At the same time, the rates of occurrence of underweight, stunting and anaemia among children under 5years were $8.0 \%, 20.3 \%$ and $14.2 \%$, respectively. It is noticeable that almost one-third $(31.9 \%)$ of children aged 6-11 months were anaemic, which was the highest among children under-five years. ${ }^{21}$ These percentages can be translated into large absolute numbers of children in China. While the stunting rate was reduced by two-thirds between 1990 and $2010,{ }^{21}$ it was estimated that 8.82 million children in China were still stunted in $2010 .^{21}$

The poor IYCF practices and nutritional status of children indicated that the recommendations from WHO and UNICEF have not been put into practice.
Therefore, the challenge is how to effectively translate the IYCF recommendations into caregivers' feeding behaviours in China, thereby enhancing children's dietary intake and growth. However, the delivery channels for IYCF recommendations were not fully assessed for their usage and potential in previous studies in China. Thus, our study used a full range of globally standard breastfeeding and complementary feeding indicators to assess the feeding practices of caregivers in one rural county in China. In addition, information on delivery channels was collected with the aim of filling this gap and providing a basis for development of effective IYCF strategies.

\section{MATERIALS AND METHODS Survey setting}

We conducted a cross-sectional household survey in Zhao County in Hebei Province in 2011. Hebei province is located in the northern part of the North China Plain, with an annual per capita net income of rural residents of $¥ 5958$ (US\$946) in $2010,{ }^{22}$ which was nearly the same as the national average (¥5919). ${ }^{23}$ Zhao County is located in the middle-south part of Hebei Province. It has a total population of 571000 (with under-five population of 38019 ), and the annual per capita net income of rural residents was $¥ 6464$ (US\$1026) in 2010 (data from Zhao county statistics bureau, unpublished). There are four county-level hospitals, 16 township hospitals and 281 village clinics in Zhao County.

\section{Survey instrument}

The maternal, newborn and child health (MNCH) household survey (unpublished, 2009) was used as the survey instrument. It was developed by the WHO and has previously been used in Cambodia, Papua New Guinea and Vietnam. ${ }^{24}$ We translated the standard WHO household survey from English into Chinese, and adapted the survey following a consultation with Chinese experts and three pilot studies. The instrument collects data on the coverage of key child health interventions, delivery channels, reasons for coverage failure and health expenditure. The survey used in this study included modules on antenatal care, delivery and neonatal care, breastfeeding and nutrition, immunisation, cough and fever, diarrhoea and vitamin A. The breastfeeding and nutrition module aims to collect feeding information on children aged 0-23 months, including caregivers' feeding knowledge and practices, delivery channels and reasons for low coverage.

In 2009, WHO and UNICEF jointly published the document Indicators for Assessing Infant and Young Child Feeding Practices, and set up 15 international standard IYCF coverage indicators (eight core indicators and seven supplementary indicators), which encourages researchers in all countries to use these indicators and makes the data comparable between countries. ${ }^{25}$ To date, very few studies in China have applied these 
standard indicators to assess infant feeding practices. Studies were either focused on breastfeeding practices ${ }^{20}$ or confined to earthquake areas. ${ }^{26}$ The breastfeeding and nutrition module in the $\mathrm{MNCH}$ household survey has standard questions for delivery channels and reasons for coverage failure, but only three core IYCF coverage indicators. Therefore, we inserted questions on the remaining core coverage indicators from the IYCF instrument to complete our survey instrument.

\section{Participants}

Caregivers in Zhao County were eligible to participate in the survey if they had a child aged 0-23 months. Mothers were the primary target group for the breastfeeding and nutrition module. If mothers were not at home or did not live with the child for any reason, other caregivers were interviewed to collect other information, such as basic household characteristics, cough and fever, diarrhoea and immunisation.

\section{Sample size and sampling}

The sample size for the survey was based on a planned cluster randomised control trial in Zhao County. The trial aims to develop and test the (cost-) effectiveness of scaled-up integrated child health interventions. The MNCH household survey was used as the baseline assessment for the trial. The sample size calculation and sampling method were based on the requirement of the trial, with townships as the randomisation unit (8 townships per group).

We expected that the anaemia prevalence would decrease from $30 \%$ to $20 \%$, with a power of $80 \%$ and a design effect of 2 and $5 \%$ as the significance level. We calculated that a sample size of 800 children under 2 years for each group would be sufficient. For feeding knowledge indicators, we expected that the proportion of knowing duration of exclusive breastfeeding, knowing duration of breastfeeding and knowing time of first introducing complementary foods would increase from $41 \%$ to $80 \%, 6 \%$ to $80 \%$ and $59 \%$ to $80 \%$, respectively. We calculated that samples of 241, 206 and 342 would be enough for each proportion. Therefore, we used the size 800 for each group as our final sample size. Meanwhile, we over-sampled $30 \%$ of children to compensate for possible refusal and loss to follow-up. We used a two-stage sampling procedure to select children for this survey. In the first stage, clusters were selected using proportional to population size sampling, with 10 clusters chosen from each township. In the second stage, the name list of all eligible children under 2 years in each village was obtained and 13 children per cluster were randomly selected using Microsoft Excel (V.2007) software. We interviewed 10 caregivers out of 13 sampled children in each cluster based on the order in which they came to the village clinic. If less than 10 sampled children were available, we asked village doctors to help us to find other children from the name list who lived nearest to the village clinics and were in the same age groups. We used those children as substitutes for the unavailable children.

\section{Training of interviewers}

We recruited 30 students from Hebei United University School of Public Health as interviewers. We trained them for 3 days, of which half a day was for field practice. The training included communication skills, explanation of questionnaires, demonstration, role plays, field practice and group discussions. The survey supervisors were all from the Capital Institute of Pediatrics, Beijing.

\section{Data collection}

We used smartphones to record data instead of traditional pen-and-paper data collection, with the standardised MNCH household survey questionnaire set-up in special developed software. We tested and used smartphones for the MNCH survey several times in the field. ${ }^{27}$

We carried out the survey from 15 to 24 August 2011 (10 days). Three teams of interviewers carried out the survey, with 10 interviewers and 2 supervisors in each team. Interviewers first introduced mothers or other caregivers to the aim of the survey and obtained written informed consent. Then the interviewers questioned the mothers or other caregivers following the instructions on the smartphone. Once an interviewer completed a questionnaire, the data were wirelessly uploaded into an Excel database via the internet server. Then the data were saved in the memory card of the smartphone as a text file to have a backup. We gave each mother a towel (worth $¥ 5$, equal to US\$0.79) to show our appreciation for their participation.

\section{Data analysis}

Data uploaded onto an internet server were automatically transformed into a Microsoft Excel sheet. After the data cleaning, we converted the database into data base file (dbf) for the final analysis. We carried out statistical analysis with SAS V.9.1 for Windows. We presented the descriptive results of our findings; data are reported with percentages, except for age of parents, which is reported as a median and range.

\section{RESULTS}

\section{Participants}

A total of 1601 caregivers of children under 2 years were interviewed. Among them, 90.1\% (1443) were mothers, $8.6 \%$ (138) were grandparents, $1.1 \%$ (17) were fathers and $0.2 \%$ (9) were others (such as uncles and aunts). Table 1 presents the characteristics of children and their parents. Among 1601 children surveyed, 57.7\% were aged $0-11$ months and $43.3 \%$ were aged 12-23 months. The gender ratio (boys to girls) of children surveyed was 138:100. The median age of mothers was 27 years (ranging from 20 to 43 years) and the median age of father was 28 years (ranging from 22 to 49 years). 
Table 1 Characteristics of surveyed children and their parents

\begin{tabular}{|c|c|c|}
\hline Category & Subcategory & Results (\%) \\
\hline \multicolumn{3}{|l|}{ Children* } \\
\hline Age group & $0-11$ & $923(57.7)$ \\
\hline (months) & $12-23$ & 678 (42.3) \\
\hline \multirow[t]{2}{*}{ Gender } & Boys & 916 (57.2) \\
\hline & Girls & $685(43.8)$ \\
\hline \multicolumn{3}{|l|}{ Mothers† } \\
\hline \multirow[t]{2}{*}{ Education } & $\begin{array}{l}\text { Completed junior high } \\
\text { school ( } 9 \text { years) }\end{array}$ & $1117(70.6)$ \\
\hline & $\begin{array}{l}\text { Completed senior high } \\
\text { school ( } 12 \text { years) }\end{array}$ & 158 (10.0) \\
\hline \multicolumn{3}{|l|}{ Fathers $†$} \\
\hline \multirow[t]{2}{*}{ Education } & $\begin{array}{l}\text { Completed junior high } \\
\text { school ( } 9 \text { years) }\end{array}$ & 1149 (72.7) \\
\hline & $\begin{array}{l}\text { Completed senior high } \\
\text { school (12 years) }\end{array}$ & $158(10.0)$ \\
\hline
\end{tabular}

Overall, the education of fathers and mothers was good; more than $80 \%$ of them had completed at least 9 years of education.
Knowledge and practices of IYCF

As shown in table 2, the knowledge of caregivers about feeding recommendations and feeding practices were generally suboptimal. Around one-third of mothers knew to initiate breastfeeding within $1 \mathrm{~h}$ of birth, while only about one-fifth of mothers followed the recommendation. Moreover, the practice of exclusive breastfeeding for 6 months was even worse. Although only less than $10 \%$ of mothers knew to continue breastfeeding up to the age of two and to give children meat at the age of 6-8 months, only $38.2 \%$ and $32.5 \%$ of children were breastfed for 2 years and were given iron-rich or ironfortified foods, respectively.

The main reasons for not initiating breastfeeding early were caesarean section, seeing the baby later than $1 \mathrm{~h}$ after delivery, not knowing about early initiation of breastfeeding and having no breast milk (figure 1). Twenty-two per cent of the mothers received advice on non-exclusive breastfeeding from relatives and $7 \%$ of them from health workers (figure 2).

\section{Utilisation of healthcare services}

Table 3 indicates that the maternal and child healthcare services were generally available and utilised by pregnant women, mothers and children, except for postnatal care.

Table 2 Knowledge and practices of caregivers on key IYCF indicators

\begin{tabular}{|c|c|c|c|}
\hline & $\begin{array}{l}\text { Number of mothers who } \\
\text { responded positive on the } \\
\text { particular knowledge/ } \\
\text { practices }\end{array}$ & $\begin{array}{l}\text { Total number of } \\
\text { mothers eligible } \\
\text { for the question }\end{array}$ & $\begin{array}{l}\text { Percentage (\%) } \\
(95 \% \mathrm{Cl})\end{array}$ \\
\hline $\begin{array}{l}\text { Mothers knowing to initiate breastfeeding within } 1 \mathrm{~h} \\
\text { of birth }\end{array}$ & 469 & 1443 & 32.5 (30.1 to 34.9$)$ \\
\hline $\begin{array}{l}\text { Children who were initiated breastfeeding within } 1 \mathrm{~h} \\
\text { of birth }\end{array}$ & 317 & $1417^{*}$ & 22.4 (20.2 to 24.6$)$ \\
\hline $\begin{array}{l}\text { Mothers knowing the duration of exclusive } \\
\text { breastfeeding }\end{array}$ & 539 & 1443 & 37.3 (34.8 to 39.8$)$ \\
\hline Children under 6 months exclusively breastfed & 40 & $414 \dagger$ & 9.7 (6.8 to 12.6$)$ \\
\hline $\begin{array}{l}\text { Mothers knowing continued breastfeeding until } \\
2 \text { years }\end{array}$ & 84 & 1443 & 5.8 (4.6 to 7.0$)$ \\
\hline Children breastfed until 2 years & 104 & $272 \ddagger$ & 38.2 (32.4 to 44.0$)$ \\
\hline $\begin{array}{l}\text { Caregivers knowing introduction of complementary } \\
\text { foods at } 6-8 \text { months }\end{array}$ & 759 & 1187 & $63.9(61.2$ to 66.6$)$ \\
\hline Children given complementary foods at $6-8$ months & 196 & $233 \S$ & 84.1 (79.4 to 88.8$)$ \\
\hline Caregivers knowing the minimum meal frequency & 933 & $1182 \emptyset$ & 60.0 (57.2 to 62.8$)$ \\
\hline Children given minimum meal frequency & 827 & $1187^{* *}$ & 69.7 (67.1 to 72.3$)$ \\
\hline $\begin{array}{l}\text { Caregivers knowing feeding children with meat at } \\
6-8 \text { months }\end{array}$ & 113 & $1182 \bigcap$ & 9.6 (7.9 to 11.3$)$ \\
\hline Children given iron-rich or iron-fortified foods $\dagger \dagger$ & 386 & $1187^{\star *}$ & 32.5 (29.8 to 35.2$)$ \\
\hline \multicolumn{4}{|c|}{$\begin{array}{l}\text { *Only children ever breastfed were used to calculate this indicator (from MNCH household survey guideline). } \\
\text { †Only children aged } 0-5 \text { months were used to calculate this indicator (from IYCF guideline). } \\
\text { †Only children aged } 20-23 \text { months were used to calculate this indicator (from IYCF guideline). } \\
\text { §Only children aged } 6-8 \text { months were used to calculate this indicator (from IYCF guideline). } \\
\text { १Data of five children on these two question were missing. } \\
\text { ** Only children aged } 6-23 \text { months were used to calculate this indicator (from IYCF guideline). } \\
\text { ††Suitable iron-rich or iron-fortified foods include meat, fish, poultry and liver/organ meat, commercially fortified foods specially designed for } \\
\text { infants and young children which contain iron or foods fortified in the home with a micronutrient powder containing iron or a lipid-based } \\
\text { nutrient supplement containing iron. } \\
\text { IYCF, infant and young child feeding. }\end{array}$} \\
\hline
\end{tabular}




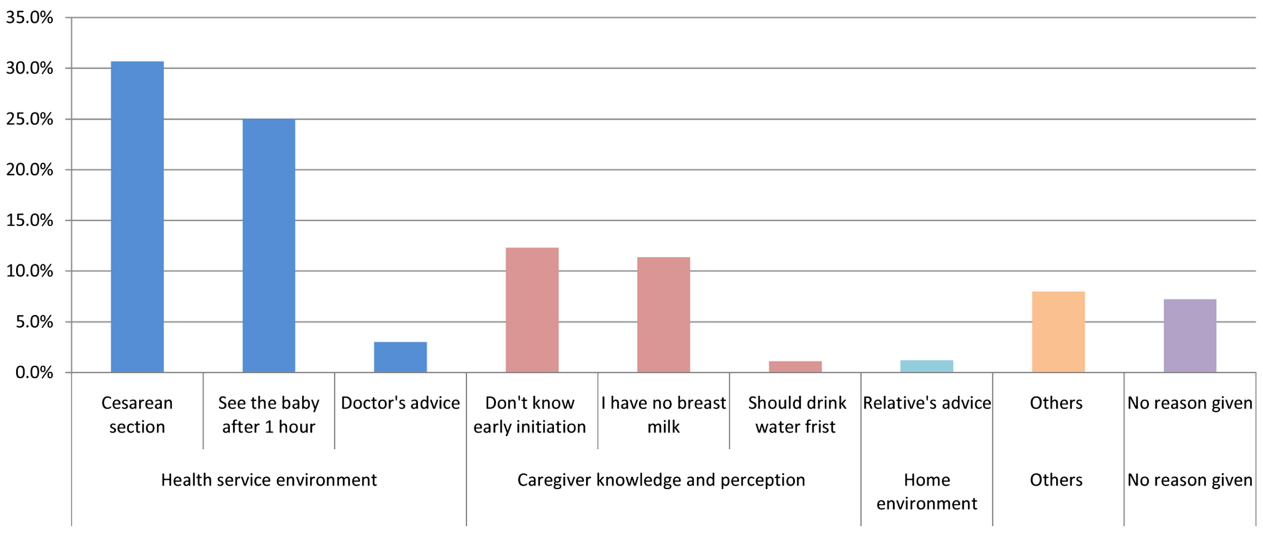

Figure 1 Distribution of reported reasons for late initiation of breastfeeding.

Only $11.4 \%$ of mothers received a home visit after delivery and $23.7 \%$ attended postnatal care at 42 days after delivery.

\section{Sources of infant feeding information}

Table 4 shows that only around one-fourth of mothers ever received feeding information during pregnancy and after delivery. Table 5 describes the sources of feeding information through which mothers received information. The leading sources were family members, neighbours, friends and popular media; these accounted for around $80 \%$ of the total information. Only around $20 \%$ of the information came from health facilities and nearly none came from the community.

\section{Household property}

Table 6 indicates that nearly all households owned a television and a mobile phone. More than $60 \%$ of the households owned computers, with $54.8 \%$ having access to internet.

\section{DISCUSSION}

We found in our survey that caregivers' feeding practices were poor, which was consistent with the national data as indicated in the Introduction of this paper. In addition, we found that the healthcare services were generally available and utilised by pregnant women and mothers, with notable exception of home visits, and visits to the health facility at 42 days after delivery. National data also showed that the proportions of women who ever received antenatal care and postnatal care were $93.7 \%$ and $91.0 \%$, respectively. In addition, the hospital delivery rate was $98.7 \%{ }^{28}$ However, high utilisation of health services was not translated into high coverage of interventions.

Mothers need support not only from the healthcare system but also from the family, community and workplace to initiate and sustain optimal breastfeeding and complementary feeding practices. ${ }^{10}$ Mothers also need consistent IYCF messages that are reinforced through multiple channels. ${ }^{29}$ Therefore, healthcare providers' engagement, community involvement and media support are all needed to maximise the effectiveness of IYCF programs. Three recommendations emerged from our study findings:

1. Strengthening the quality of care at health facilities to improve feeding counselling: China initiated the national Basic Public Health Service program ${ }^{30}$ to provide universal basic public health services for all residents. Maternal and child healthcare workers are required by the programme to provide face-to-face counselling to pregnant women during antenatal care visits and hospital delivery, and to mothers of young children during newborn home visits, postnatal care visits and child healthcare visits. ${ }^{31}$ However, rural health workers in China generally have poor education and

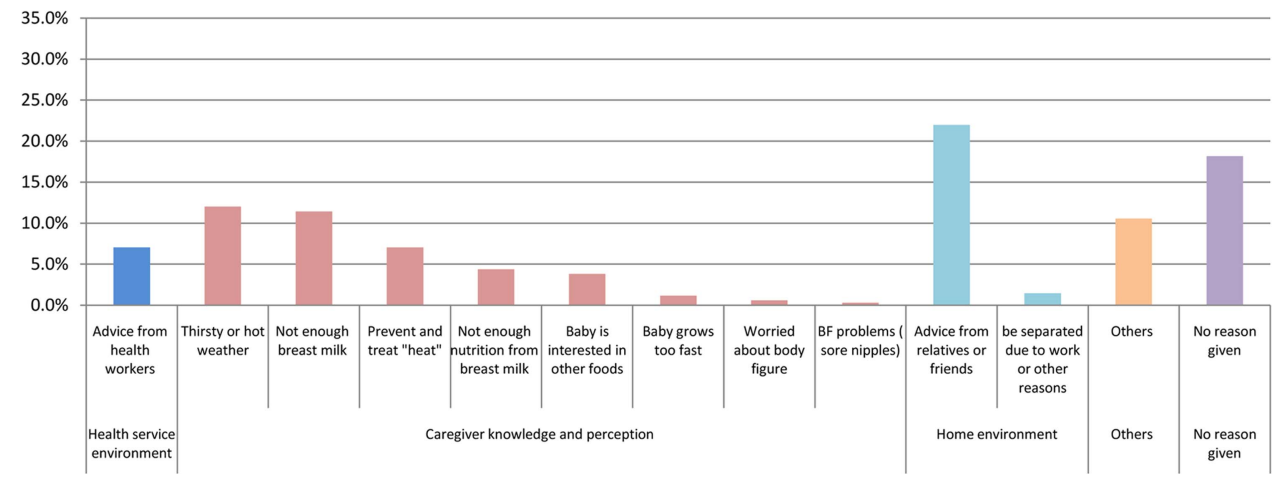

Figure 2 Distribution of reasons for non-exclusive breastfeeding. 
Table 3 Utilisation of healthcare services by pregnant women, mothers and children

\begin{tabular}{|c|c|c|c|}
\hline & $\begin{array}{l}\text { Number of mothers who } \\
\text { responded positive on the } \\
\text { particular knowledge/practice }\end{array}$ & $\begin{array}{l}\text { Total number of } \\
\text { mothers eligible for } \\
\text { the question }\end{array}$ & $\begin{array}{l}\text { Percentage (\%) } \\
(95 \% \mathrm{Cl})\end{array}$ \\
\hline $\begin{array}{l}\text { Pregnant women receiving antenatal care } \\
\text { at least once }\end{array}$ & 1350 & 1443 & 93.6 (92.3 to 94.9$)$ \\
\hline $\begin{array}{l}\text { Pregnant women receiving antenatal care } \\
\text { four times or above }\end{array}$ & 1014 & 1443 & $70.3(67.9$ to 72.7$)$ \\
\hline Children delivered at hospital & 1436 & 1443 & 99.5 (99.1 to 99.9$)$ \\
\hline $\begin{array}{l}\text { Mothers and children receiving home visit } \\
\text { after delivery (within } 7 \text { days after discharge) }\end{array}$ & 165 & $1442^{*}$ & $11.4(9.8$ to 13.0$)$ \\
\hline $\begin{array}{l}\text { Mothers receiving postnatal care at } 42 \text { days } \\
\text { after delivery }\end{array}$ & 340 & $1413 \dagger$ & 24.1 (21.9 to 26.3 ) \\
\hline Children ever immunised & 1598 & 1601 & 99.8 (99.6 to 100.0$)$ \\
\hline
\end{tabular}

lack expertise in, and motivation for, their work, which generally results in low-quality healthcare services provided by rural health facilities. ${ }^{32-34}$ Our study also indicated that few mothers reported that they ever received feeding counselling from health workers, which suggested that many health workers did not provide feeding counselling. Feeding counselling was the component of antenatal care in the late phase of antenatal care, which involves the village doctor, township hospital doctor and countylevel hospital doctor. In addition, we found that the knowledge and practice of early initiation of breastfeeding were $32.5 \%$ and $22.4 \%$, respectively. Hospital delivery is a requirement in China. Therefore, it is the duty of the hospitals to ensure that deliveries take place in hospital. However, we found that more than $50 \%$ of reasons for late initiation of breastfeeding were attributed to the health facility environment, such as high caesarean section, separation of babies from mothers and doctors' advice. Also, 7\% of mothers reported that they received advice on nonexclusive breastfeeding from health workers. It was reported that the current national rate of caesarean section in China was about $40 \%$, which is the highest worldwide. $^{35} 36$ Therefore, there is a need to strengthen the quality of healthcare services provided by rural health facilities as well as to increase service coverage.

2. Mobilise community resources to deliver IYCF recommendations: Community-based breastfeeding promotion and support were proven to be effective. Therefore, the Global Strategy for Infant and Young Child Feeding recognises this as one of the key components of a comprehensive programme to improve breastfeeding practices. ${ }^{11}$ Large-scale community-based programmes have demonstrated that the community offers indispensable resources for breastfeeding promotion and support. ${ }^{37}$ In the Regional Framework for Community IMCI of WHO Western Pacific Region, breastfeeding and complementary feeding are among the 12 key family practices that can be improved through community-based programmes. ${ }^{38}$ In addition, a study in China indicated that community-based behavioural change approaches that use trained village nutrition educators to provide feeding counselling to pregnant women and mothers are effective in improving breastfeeding and complementary feeding practices. ${ }^{39}$ Therefore, communities

Table 4 Mothers ever receiving feeding information

\begin{tabular}{|c|c|c|c|}
\hline & $\begin{array}{l}\text { Number of mothers who } \\
\text { responded positive on the } \\
\text { particular knowledge/practices }\end{array}$ & $\begin{array}{l}\text { Total number of } \\
\text { mothers eligible for } \\
\text { the question }\end{array}$ & $\begin{array}{l}\text { Percentage (\%) } \\
(95 \% \mathrm{Cl})\end{array}$ \\
\hline $\begin{array}{l}\text { Receiving breastfeeding information } \\
\text { during pregnancy }\end{array}$ & 379 & 1443 & 26.3 (24.0 to 28.6 ) \\
\hline $\begin{array}{l}\text { Receiving breastfeeding information after } \\
\text { delivery }\end{array}$ & 415 & 1443 & $28.8(26.5$ to 31.1$)$ \\
\hline $\begin{array}{l}\text { Receiving complementary feeding } \\
\text { information during pregnancy }\end{array}$ & 341 & $1440^{*}$ & 23.7 (21.5 to 25.9$)$ \\
\hline $\begin{array}{l}\text { Receiving complementary feeding } \\
\text { information after delivery }\end{array}$ & 385 & $1440^{*}$ & 26.7 (24.4 to 29.0$)$ \\
\hline
\end{tabular}


Table 5 Sources of feeding information for mothers during pregnancy and after delivery

\begin{tabular}{|c|c|c|c|c|c|c|}
\hline & \multicolumn{2}{|c|}{ Breastfeeding } & \multicolumn{2}{|c|}{$\begin{array}{l}\text { Complementary } \\
\text { feeding }\end{array}$} & \multicolumn{2}{|c|}{ Formula feeding } \\
\hline & $\bar{n}$ & $\%\left(\mathrm{~N}=749^{\star}\right)$ & $\bar{n}$ & $\%\left(\mathrm{~N}=664^{\star}\right)$ & $\bar{n}$ & $\%\left(\mathrm{~N}=244^{\star}\right)$ \\
\hline Family members/neighbours/friends & 276 & 36.8 & 316 & 47.6 & 144 & 59.0 \\
\hline Popular media & 312 & 41.7 & 228 & 34.3 & 5 & 2.0 \\
\hline Health facility & 160 & 21.4 & 120 & 18.1 & 65 & 26.6 \\
\hline Community & 1 & 0.1 & 0 & 0.0 & 1 & 0.4 \\
\hline Formula company & - & - & - & - & 29 & 11.9 \\
\hline Total & 749 & 100.0 & 664 & 100.0 & 244 & 100.0 \\
\hline
\end{tabular}

hold potential to effectively deliver IYCF recommendations in rural China.

The rates of knowledge and practice of 6-month exclusive breastfeeding were $37.3 \%$ and $9.7 \%$ respectively. Thus, there is a gap in breastfeeding and exclusive breastfeeding practices. In our study site, most village doctors were men. Other resources from the community have the potential to provide the support for exclusive breastfeeding. Our data showed less than one in a hundred mothers received feeding information from their communities. Studies have shown that peer counselling and lay counselling are effective in promoting breastfeeding. ${ }^{40-43}$ In rural China, existing community resources could be mobilised, such as the village women cadres, family planning workers, primary school teachers and volunteers, to provide feeding counselling to pregnant women and mothers.

3. Utilise popular media as well as internet and mobile phones to expand IYCF coverage: According to our results, the leading sources of feeding information were family members, neighbours, or friends and popular media (newspaper, magazine, book, radio and television: around $80 \%$ of information on breastfeeding and complementary feeding came from these two sources, whereas only $20 \%$ came from health facilities).

As those two main sources are both important, they should be fully used to disseminate accurate infant feeding information. However, we noted that some information from these two sources was invalid. As indicated in the results, around $60 \%$ of inaccurate advice to use formula feeding and more than $20 \%$ of inaccurate information on non-exclusive breastfeeding originated from family members, neighbours and friends. Therefore, much more effort must be made to strengthen these channels in terms of ensuring provision of correct information and broadening its scope to provide more mothers with accurate feeding advice.

Since two-thirds of mothers received no advice on feeding, new channels, such as internet and mobile phones, could be explored. Evidence indicates that computer-tailored nutrition education is an innovative and promising tool to motivate people to make healthy dietary changes. ${ }^{44}$ Also, a recent study showed that internet nutrition education can be a viable alternative to traditional nutrition education for increasing the fruit and vegetable consumption of women, infants and children. $^{45}$

With the rapid socio-economic development and technical progress, many Chinese people have access to new information and communication technologies. Data showed that, by the end of 2013, there were 1229 million mobile phone users and 618 million internet users in China. ${ }^{46}$ Our survey showed that in Zhao County, nearly all households owned mobile phones, and more than $60 \%$ of households owned computers, with more than half of them having access to internet. In addition, the young generation of parents is well educated; around $95 \%$ of fathers and mothers attended junior high school (9 years of education). This implies a potential to deliver feeding recommendations through

Table 6 Households owning a radio, television, mobile phone, computer and accessing to the internet

\begin{tabular}{lccc}
\hline & $\begin{array}{l}\text { Number of mothers who } \\
\text { responded positive on the } \\
\text { particular knowledge/practices }\end{array}$ & $\begin{array}{l}\text { Total number of } \\
\text { mothers eligible for } \\
\text { the question }\end{array}$ & $\begin{array}{l}\text { Percentage (\%) } \\
(95 \% \mathbf{C l})\end{array}$ \\
\hline Households owning a radio & 377 & 1601 & $23.6(21.5$ to 25.7) \\
Households owning a television & 1600 & 1601 & $99.9(99.7$ to 100) \\
Households owning a mobile phone & 1591 & 1601 & $99.4(99.0$ to 99.8) \\
Households owning a computer & 979 & 1601 & $61.2(58.8$ to 63.6) \\
Households with access to the internet & 876 & 1600 & $54.8(52.4$ to 57.2) \\
at home & & & \\
\hline
\end{tabular}


mobile phones or the internet. Future studies are needed to test the feasibility and effectiveness of these potential delivery channels in the context of rural China.

\section{CONCLUSIONS}

The findings of our study indicate that few caregivers of children in rural China received feeding information during pregnancy and after delivery. Moreover, their feeding knowledge and practices are poor, though the maternal and child healthcare services were generally available and utilised by mothers. Health facilities need to be strengthened and fully utilised to provide highquality feeding counselling. Other channels, such as community resources, popular media, internet and mobile phones, hold great potential and could also be explored in future studies to maximise the effectiveness of IYCF programs.

Acknowledgements The authors wish to thank all colleagues from the Zhao county Maternal and Child Health Hospital for coordination and logistic arrangements, and we want to thank all students from Hebei United University for their hard work as interviewers. We are indebted to all the mothers and caregivers who participated in our survey.

Contributors The study was initiated and conceptualised by $Y Z$ and RWS. YZ supervised the study. QW and YL collected and coded the data. QW performed data analysis. QW, YZ, RWS and MHvV participated in the explanation and discussion of the results. The manuscript was drafted by $Q W$, reviewed and revised by YZ, RWS, MHvV, LC, WW, YL and JC. All authors read and approved the final manuscript.

Funding The survey was funded by the Ministry of Health of China (Project No. 201002006).

Competing interests None.

Patient consent Obtained.

Ethics approval The study was approved by the Ethical Committee of Capital Institute of Pediatrics. All interviewees read the Information Sheet and provided both oral and written informed consent on behalf of the children involved in our study.

Provenance and peer review Not commissioned; externally peer reviewed.

Data sharing statement Additional data can be accessed via the Dryad data repository at http://datadryad.org/ with the doi:10.5061/dryad.bh4kt.

Open Access This is an Open Access article distributed in accordance with the Creative Commons Attribution Non Commercial (CC BY-NC 3.0) license, which permits others to distribute, remix, adapt, build upon this work noncommercially, and license their derivative works on different terms, provided the original work is properly cited and the use is non-commercial. See: http:// creativecommons.org/licenses/by-nc/3.0/

\section{REFERENCES}

1. Caulfield LE, de Onis M, Blossner M, et al. Undernutrition as an underlying cause of child deaths associated with diarrhea, pneumonia, malaria, and measles. Am J Clin Nutr 2004;80:193-8.

2. Pelletier DL, Frongillo EA Jr, Habicht JP. Epidemiologic evidence for a potentiating effect of malnutrition on child mortality. Am J Public Health 1993;83:1130-3.

3. Black RE, Victora CG, Walker SP, et al. Maternal and child undernutrition and overweight in low-income and middle-income countries. Lancet 2013;382:427-51.

4. Dewey KG, Adu-Afarwuah S. Systematic review of the efficacy and effectiveness of complementary feeding interventions in developing countries. Matern Child Nutr 2008;4(Suppl 1):24-85.
5. Shrimpton R, Victora CG, de Onis M, et al. Worldwide timing of growth faltering: implications for nutritional interventions. Pediatrics 2001;107:E75.

6. USAID. Behavior change interventions and child nutritional status: evidence from the promotion of improved complementary feeding practices. Washington: USAID, 2011.

7. WHO, UNICEF. WHO/UNICEF Regional Child Survival Strategy: accelerated and sustained action towards MDG 4 WHO Regional Office for the Western Pacific. 2006.

8. Arifeen S, Black RE, Antelman G, et al. Exclusive breastfeeding reduces acute respiratory infection and diarrhea deaths among infants in Dhaka slums. Pediatrics 2001:108:E67.

9. Bahl R, Frost $\mathrm{C}$, Kirkwood BR, et al. Infant feeding patterns and risks of death and hospitalization in the first half of infancy: multicentre cohort study. Bull World Health Organ 2005;83:418-26.

10. WHO. Community-based strategies for breastfeeding promotion and support in developing countries. Geneva: WHO, 2003.

11. WHO, UNICEF. Global strategy for Infant and Young Child Feeding. Geneva: WHO, 2003.

12. WHO. Infant and young child feeding counseling: an integrated course. Geneva: WHO, 2005.

13. Gove S. Integrated management of childhood illness by outpatient health workers: technical basis and overview. The WHO Working Group on Guidelines for Integrated Management of the Sick Child. Bull World Health Organ 1997;75(Suppl 1):7-24.

14. Center for Health Statistics Information Ministry of Health, China. An analysis report of National Health Services Survey in China. Beijing: Peking Union Medical College Press, 2009.

15. Wang WJ, Li W, Sun J, et al. Investigation on the feeding status of infants and young children in poor counties of Gansu Province. Wei Sheng Yan Jiu 2011;40:327-30.

16. Xing Y, Yan H, Dang SN. Knowledge and practice of child feeding among Tibet mothers with small children in Lhasa rural area. Chin J Public Health 2010;26:945-6.

17. Yi C, Fang G-H, Zhang F. Survey of status of complementary food in Li ethnic infants in rural areas of Hainan Province. Zhong Guo Re Dai Yi Xue 2007; 7:638-9.

18. Liu AD, Zhao L, Yu DM, et al. Study on feeding status of infants and young children under 2 years old in China. Wei Sheng Yan Jiu 2009;38:555-7.

19. Ye JL, Cui Y, Pan XP. Cross-sectional study on the current situation of breast feeding in western China rural areas. Zhonghua Yu Fang Yi Xue Za Zhi 2007;41:183-5.

20. Guo S, Fu X, Scherpbier RW, et al. Breastfeeding rates in central and western China in 2010: implications for child and population health. Bull World Health Organ 2013;91:322-31.

21. Chen $\mathrm{C}, \mathrm{He} \mathrm{W}$, Wang $\mathrm{Y}$, et al. Nutritional status of children during and post-global economic crisis in China. Biomed Environ Sci 2011;24:321-8.

22. National Bureau of Statistics of China. Statistical Communique of the People's Republic of China on the 2010 National Economic and Social Development. Beijing: National Bureau of Statistics of China, 2010.

23. Hebei Provincial Bureau of Statistics. Statistical Communiqué of the Hebei Province on the 2010 Economic and Social Development. Shijiazhuang: Hebei Provincial Bureau of Statistics, 2010.

24. Bar-Zeev N, Maclennan C, Murray J, et al. $\mathrm{IMCl}$ and health systems strengthening. Geneva: WHO, 2012.

25. WHO, UNICEF, USAID, AED, UCDAVIS, IFPRI. Indicators for assessing infant and young child feeding practices-Part 1. Introduction. WHO, 2010

26. Sun J, Huo J, Zhao L, et al. The nutritional status of young children and feeding practices two years after the Wenchuan Earthquake in the worst-affected areas in China. Asia Pac J Clin Nutr 2013:22:100-8.

27. Zhang $\mathrm{S}, \mathrm{Wu} \mathrm{Q}$, van Velthoven $\mathrm{MH}$, et al. Smartphone versus pen-and-paper data collection of infant feeding practices in rural China. J Med Internet Res 2012;14:e119.

28. Ministry of Health China. Statistical Communiqué of the People's Republic of China on the 2010 Health Care Development. Beijing: Center for Statistics Information Ministry of Health, P.R.China, 2012

29. DiClemente RJ, Crosby RA, Kegler MC. Emerging theories in health promotion practice and research. San Francisco: Wiley, 2009.

30. T Z. China launched basic public health services program. Xinhua News Agency, 2009, 12 July.

31. Ministry of Health China. Implementation guidelines on national basic public health service program (2009). Ministry of Health, 2009, 16 October.

32. Zhu XL, Dai T, Wang F, et al. Analysis on the major problems in implementation of equalization of essential public health services in China. Chinese J Soc Med 2011;28:4 
33. Qiao YH, Li C, Hao JZ, et al. Analysis and suggestion of implementation of the basic public health service equalization in Hebei province. Med Res Educ 2012;29:7.

34. Zhang Y, Cao ZH, Han CX, et al. Research on basic public health services in Hebei province. Sci Technol Info 2012;24:2.

35. Feng XL, Wang Y, An L, et al. Cesarean section in the People's Repulic of China: current perspectives. Int $J$ Womens Health 2014;6:59-74. e

36. Mi J, Liu F. Rate of caesarean section is alarming in China. Lancet 2014;383:1463-4.

37. WHO. Learning from large-scale community-based programmes to improve breastfeeding. Geneva: WHO, 2008.

38. (WPRO) WHOWPR. Regional framework for community IMCI. Geneva: WHO, 2003

39. Guldan GS, Fan HC, Ma X, et al. Culturally appropriate nutrition education improves infant feeding and growth in rural Sichuan, China. J Nutr 2000;130:1204-11.

40. Haider R, Ashworth A, Kabir I, et al. Effect of community-based peer counsellors on exclusive breastfeeding practices in Dhaka, Bangladesh: a randomised controlled trial [see comments]. Lancet 2000;356:1643-7.
41. Morrow AL, Guerrero ML, Shults J, et al. Efficacy of home-based peer counselling to promote exclusive breastfeeding: a randomised controlled trial. Lancet 1999;353:1226-31.

42. Tylleskar T, Jackson D, Meda N, et al. Exclusive breastfeeding promotion by peer counsellors in sub-Saharan Africa (PROMISEEBF): a cluster-randomised trial. Lancet 2011;378:420-7.

43. Nor B, Ahlberg BM, Doherty T, et al. Mother's perceptions and experiences of infant feeding within a community-based peer counselling intervention in South Africa. Matern Child Nutr 2012;8:448-58.

44. Brug J, Oenema A, Campbell M. Past, present, and future of computer-tailored nutrition education. Am J Clin Nutr 2003; 77(4 Suppl):1028S-34S.

45. Bensley RJ, Anderson JV, Brusk JJ, et al. Impact of internet vs traditional Special Supplemental Nutrition Program for Women, Infants, and Children nutrition education on fruit and vegetable intake. J Am Diet Assoc 2011;111:749-55.

46. National Bureau of Statistics of China. Statistical Communique of the People's Republic of China on the 2013 National Economic and Social Development. Beijing: National Bureau of Statistics of China, 2013. 